\title{
Job Embeddedness and Organizational Climate
}

\author{
Hasnizawati Hashima, Noormala Amir Ishak ${ }^{b}$ Zulkifli Ab. Ghani Hilmic \\ aFaculty of Business Management, Universiti Teknologi MARA, 40450 Shah Alam, Malaysia \\ bArshad Ayub Graduate Business School, Universiti Teknologi MARA, 40450 Shah Alam, Malaysia \\ cFaculty of Computer \& Mathematical Sciences, Universiti Teknologi MARA Pahang,26400Jengka, Malaysia \\ hasnizawati@pahang.uitm.edu.my
}

\begin{abstract}
Issues regarding persons with disability (PWD) at workplace have become an endless argument. PWD faced difficulties at their workplaces after struggling to get the job. They faced with problems that could not make them work longer. This paper examines the relationship between organizational climate and their job embeddedness. It reveals that disabled employees must be supported by an appropriate organizational climate to ensure their embeddedness with the company. The findings can be used in the creation of a better organizational climate specially prepared for the disabled employees as part of the company's responsibilities as the PWD have their rights in receiving the same treatment as received by other normal employees.
\end{abstract}

Keywords: Organizational Climate; Job Embeddedness; Disabled Employee; Person with Disability

eISSN: 2398-4279 @ 2017. The Authors. Published for AMER ABRA by e-International Publishing House, Ltd., UK. This is an open access article under the CC BY-NC-ND license (http://creativecommons.org/licenses/by-ncnd/4.0/). Peer-review under responsibility of AMER (Association of Malaysian Environment-Behaviour Researchers), ABRA (Association of Behavioural Researchers on Asians) and cE-Bs (Centre for EnvironmentBehaviour Studies), Faculty of Architecture, Planning \& Surveying, UniversitiTeknologi MARA, Malaysia.

https://doi.org/10.21834/ajqol.v2i6.44 


\subsection{Introduction}

The issues on a person with disability (PWD) at workplace have been an endless discussion amongst researchers (Adabi, 2011). Extensive research reports and government efforts portray an array of suggestions to look up and improve ways on the employers' decisions. Thus, there is an articulated need to generate ideas and enhance strategies to ensure the employability of PWD can be recognized and well implemented. The revised of Persons with Disabilities Act, 2008 (Act 685) has shown a constant and undivided support given by the Malaysian government in helping the disabled tostep in the economy and develop their potential. However, the effort is complicated enough to be realized. Company employing disabled may come across challenges at the first phase of hiring due to the matching process between the job and the impairment (Furuoka, Lim, Pazim\& Mahmud; 2011, Newton, Ormerod\& Thomas, 2007). Conversely, research has also shown that hiring disabled may have their positive impacts. Buciuniene and Kazlauskaite (2010) and Ta and Leng (2013) postulated that despite the difficulties faced by the company in hiring the disabled, they can be very loyal with their work. It was noted that disabled people are happier at job than non-disabled employees as they have certain expectations on the job that they can achieve (Pagan-Rodriguez, 2009). Companies that hire disabled people are given incentives to encourage them in employing more disabled (Person with Disabilities Act, 2008).This may help employers in creating a better working environment which can attract disabled job seekers and retain good employers' image in the society. Past studies have elucidated that organizational climate is positively related to social interaction (Chen \& Huang, 2007) and will be more satisfied with their jobs as well as become high performers (Jackofsky\& Slocum Jr., 1988). However, previous researchers have not given consistent attention concerning the effect of disabled employee on their decision to stay on their job as the turnover of them is still high (Social Welfare Department, 2012). There is still lack of research focus in this area that this study will examine the possibility of organizational climate as a predictor of disabled job embeddedness in Malaysia. Therefore, this research hopes to reveal whether organizational climate positively influence disabled job embeddedness or not.

\subsection{Literature Review}

\subsection{Job Embeddedness}

Mitchell, Holtom, Lee, Sablynski and Erez (2001) suggested that people is attached in a social web that holds them based on three key characteristics which are referred to as links, fit and sacrifice. Furthermore, they are concerned with "on-the-job" and "off-the-job" experiences. The more connected an employee is with the social web, the more embedded he or she is. Job embeddedness three key dimensions examined in this study are links, fit and sacrifice. Links refer to the formal or informal connections between the individual and 
the institutions (Mitchell et al., 2001). The more an employee has the number of thread attached with his or her organization (e.g., work groups) and the community (e.g., belonging to local interest group), the more embedded they will become. Fit is the individual's perceived compatibility with an organization or environment (Mitchell et al., 2001). Employees will feel comfort with the organization if they find that their personal values or goals fit with their jobs or community. Sacrifice is defined as the material cost or psychological benefits that may be forfeited if the employees leave their job (Mitchell et al., 2001). These dimensions are associated with an individual's organization and community.

If employees have no alternative job when they decide to quit from the organization, consideration should be given to the forces of attachment to the organization rather than the forces to leave (Maert Jr. \&Griffeth, 2004). Thus, the main objective in this study is on how job embeddedness relates with another work related variable that is the organizational climate. It is believed that employees with high level of job embeddedness will reflect more connection (links) with the organization, have well feeling of comfort with their job which suits with their personal goal (fit) and they will sacrifice valued things if they leave their job (Sekiguchi, Burton \&Sablynski, 2008). In other words, when employees with disability feel attached to the job, they could stay longer with the organization.

\subsection{Organizational Climate}

Denison (1996) defined organizational climate as organizational members' perceptions of observable practices and procedures that are closer to the surface of organizational life. Castro and Martins (2010) pointed organizational climate in their study as shared perceptions, feelings and attitudes that members of the organization have about the basic elements that reflect the norms, values and attitudes of the organization's culture and influence positively or negatively the individual's behavior. Organizational climate is a meaningful concept that brings significant inference to recognize employee's behavior in an organization especially for the employees with disability. It takes place when employees perceive that the climate of their organization as a great place to work for which eventually will make them "stick" with the organization (Mitchell \& Lee, 2001).

In this study, definitions by Castro and Martins (2010), Denison (1996) and Schneider et al. (1996) were integrated. Therefore, organizational climate is defined as common perceptions, emotions, and behaviors that members of the organization have which reveal the essential norms, values and attitudes possessed.

\subsection{Organizational climate and job embeddedness}

Empirical evidence had shown a significant relationship between organizational climate and job satisfaction (Schyns, Veldhoven\& Wood, 2009), employee retention (Gentry, Kuhnert, Mandore\& Page, 2007), and employee's intention to leave (Stone, Mooney-Kane, Larson, Pastor, Zwanziger\& Dick, 2007). These researchers have successfully found evidence that organizational climate experienced by the employees can have the powerful influence on employee's behavior. Therefore, organizational climate is believed to influence an 
constructs. The research hypothesis was tested using structural equation modelling (SEM). Model fit (Goodness of Fit indexes), regression coefficient, coefficient of determination $\left(R^{2}\right)$ and significance of paths for the proposed model were analysed.

\subsection{Results and Discussions}

Out of the 114 disabled employees that participated in the study voluntarily, $63.2 \%$ were males and $36.8 \%$ females. In terms of age category, $3.5 \%$ were less than 20 years old, $45.6 \%$ between 20 to 29 years old, $33.3 \%$ between 30 to 39 years old, $17 \%$ between 40 to 49 years old and $2.6 \%$ more than 50 years old. The highest type of disability was physical $(45.6 \%)$, followed by hearing impaired $(43.9 \%)$, visual and speech disability, both $5.3 \%$ each. Most of the respondents were unmarried $(67.5 \%)$, married $(28.9 \%)$ and divorced (3.5\%). Majority were born with a disability (64.9\%) and $35.1 \%$ due to accidents. Organizational climate was estimated using five latent sub-constructs which were measured by a number of items. CFA was performed on these five sub-constructs. After removing items with factor loadings less than 0.6 for already established items or 0.5 for newly developed items (Zainudin, 2012), three sub-constructs were retained namely warmth, reward and structure with two usable items each. Then, the second order CFA was performed. The results is shown in Table 1.

\begin{tabular}{|c|c|c|}
\hline Path & $\begin{array}{c}\text { Factor Loadings for } \\
\text { 1stOrder CFA }\end{array}$ & $\mathrm{R}^{2}$ \\
\hline Warmth $\rightarrow$ OCwarm1 & 0.79 & 0.63 \\
\hline Warmth $\rightarrow$ OCwarm2 & 0.70 & 0.49 \\
\hline Reward $\rightarrow$ OCrew2 & 0.95 & 0.90 \\
\hline Reward $\rightarrow$ OCrew3 & 0.56 & 0.31 \\
\hline Structure $\rightarrow$ OCstr1b & 0.84 & 0.71 \\
\hline Structure $\rightarrow$ OCstr1a & 0.57 & 0.33 \\
\hline Path & $\begin{array}{c}\text { Factor Loadings for } 2^{\text {nd }} \\
\text { Order CFA }\end{array}$ & $\mathrm{R}^{2}$ \\
\hline $\mathrm{OC} \rightarrow$ Warmth & 0.86 & 0.73 \\
\hline $\mathrm{OC} \rightarrow$ Rewards & 0.61 & 0.37 \\
\hline $\mathrm{OC} \rightarrow$ Structure & 0.77 & 0.59 \\
\hline
\end{tabular}

The factor loading of organizational climate on warmth, rewards and strategy are 0.86 , 0.61 and 0.77 with $R^{2} \quad 0.73,0.37$ and 0.59 respectively. Thus, the contribution of organizational climate on warmth and structure are good while on rewards it is moderate. How fit the model to the data is shown through several fitness indexes. The absolute fit, incremental fit and parsimonious fit achieved the required level as shown in Table 2. 
Table 2: Fitness for Measurement Model of Organizational Climate

\begin{tabular}{lccc}
\hline Category & Fitness Index & Index Value & Acceptance Level \\
\hline Absolute Fit & p-value & 0.402 & $>0.05$ \\
& RMSEA & 0.017 & $<0.08$ \\
& GFI & 0.982 & $>0.90$ \\
\hline Incremental Fit & AGFI & 0.936 & $>0.90$ \\
& CFI & 0.999 & $>0.90$ \\
& TLI & 0.997 & $>0.90$ \\
& NFI & 0.964 & $>0.90$ \\
\hline Parsimonious Fit & Chisq / df & 1.031 & $<5.0$ \\
\hline
\end{tabular}

RMSEA, root mean square of error approximation; GFI, goodness of fit index; AGFI, adjusted goodness of fit; CFI, comparative fit index; TLI, Tucker-Lewis index; NFI, normed fit index; Chisq/df, Chi square / degrees of freedom

(Zainudin, 2012)

The reliability and validity measures for the constructs in the measuring model are shown in Table 3.

\begin{tabular}{|c|c|c|c|c|}
\hline & Construct & $\begin{array}{l}\text { Cronbach Alpha } \\
\text { (above 0.60) }\end{array}$ & $\begin{array}{l}\text { Critical Ratio } \\
\text { (above } 0.60 \text { ) }\end{array}$ & $\begin{array}{c}\text { Average Variance } \\
\text { Extracted (above } \\
0.50)\end{array}$ \\
\hline Warmth & & 0.71 & 0.72 & 0.56 \\
\hline Reward & & 0.69 & 0.74 & 0.61 \\
\hline Structure & & 0.65 & 0.67 & 0.52 \\
\hline
\end{tabular}

The values in Table 3 indicate that the convergent validity, construct validity, discriminant validity, the internal and composite reliability for sub-constructs of Organizational Climate achieved the required level. (Zainudin, 2012)

The path analysis and its significance are shown in Table 4.

Table 4: The Regression Weight of OC on its Sub-Constructs and its Significance

\begin{tabular}{lccccccc}
\hline & Path & & Estimate & $\begin{array}{c}\text { Std. } \\
\text { Error }\end{array}$ & $\begin{array}{c}\text { Critical } \\
\text { Ratio. }\end{array}$ & $\begin{array}{c}p- \\
\text { value }\end{array}$ & Result \\
\hline Warmth & $<--$ & OC & 1.000 & \multicolumn{5}{c}{ Reference Point } & Sig \\
Reward & $<--$ & OC & .590 & .227 & 2.605 & .009 & Sig \\
Structure & $<--$ & OC & .746 & .251 & 2.976 & .003 & Sig \\
\hline
\end{tabular}

Organizational climate has significant effects on three sub-constructs (warmth, reward, structure) while decision making and risk were not included in the measurement model.The same CFA procedure was repeated for job embeddedness on its three sub-constructs. After removing items with factor loadings less than 0.6 , two sub-constructs were retained namely fit and sacrifice with three usable items for fit and sacrifice. After the CFA procedure prepared, two of the items from link show that they belong to another new subconstructs 
and it is named as satisfaction. Then, the second order CFA was performed with the following results.

Table 5: First and Second Order CFA Results for Job Embeddedness Constructs

\begin{tabular}{|c|c|c|}
\hline Path & $\begin{array}{l}\text { Factor Loadings for } \\
\text { 1st Order CFA }\end{array}$ & $\mathrm{R}^{2}$ \\
\hline Fit $\rightarrow$ JEfit4 & 0.74 & 0.54 \\
\hline Fit $\rightarrow$ JEfit6 & 0.68 & 0.46 \\
\hline Fit $\rightarrow$ Jefit7 & 0.75 & 0.56 \\
\hline Sacrifice $\rightarrow$ JEsac2 & 0.63 & 0.40 \\
\hline Sacrifice $\rightarrow$ JEsac4 & 0.81 & 0.65 \\
\hline Sacrifice $\rightarrow$ JEsac5 & 0.65 & 0.43 \\
\hline $\begin{array}{ll}\text { Satisfaction } & \rightarrow \\
\text { Jesatis2 } & \end{array}$ & 0.74 & 0.55 \\
\hline $\begin{array}{l}\text { Satisfaction } \\
\text { Jesatis3 }\end{array}$ & 0.75 & 0.56 \\
\hline Path & $\begin{array}{l}\text { Factor Loadings for } \\
2^{\text {nd }} \text { Order CFA }\end{array}$ & $\mathrm{R}^{2}$ \\
\hline $\begin{array}{l}\text { Job Embeddedness } \rightarrow \\
\text { Fit }\end{array}$ & 0.96 & 0.93 \\
\hline $\begin{array}{l}\text { Job Embeddedness } \rightarrow \\
\text { Sacrifice }\end{array}$ & 0.75 & 0.56 \\
\hline $\begin{array}{l}\text { Job Embeddedness } \rightarrow \\
\text { Satisfaction }\end{array}$ & 0.77 & 0.59 \\
\hline
\end{tabular}

The factor loading of job embeddedness on fit, sacrifice and satisfaction are $0.96,0.75$ and 0.77 with $\mathrm{R}^{2} 0.93,0.56$ and 0.59 respectively. Thus, the contribution of job embeddedness on fit, sacrifice and satisfaction are good. The absolute fit, incremental fit and parsimonious fit achieved the required level as shown in Table 6.

\begin{tabular}{lccc}
\multicolumn{4}{l}{ Table 6: Assessment of Fitness for Measurement Model of Job Embeddedness } \\
\hline \multicolumn{1}{l}{ Category } & Fitness Index & Index Value & Acceptance Level \\
\hline Absolute Fit & p-value & 0.27 & $>0.05$ \\
& RMSEA & 0.04 & $<0.08$ \\
& GFI & 0.96 & $>0.90$ \\
\hline Incremental Fit & AGFI & 0.92 & $>0.90$ \\
& CFI & 0.99 & $>0.90$ \\
& TLI & 0.98 & $>0.90$ \\
& NFI & 0.94 & $>0.90$ \\
\hline Parsimonious Fit & Chisq / df & 1.18 & $<5.0$ \\
\hline
\end{tabular}


The reliability and validity measures for the constructs in the measuring model are shown in Table 7.

\begin{tabular}{lccc}
\multicolumn{3}{l}{ Table 7. Reliability and Validity Measures for Sub-constructs of Job Embeddedness } \\
\cline { 2 - 4 } Construct & $\begin{array}{c}\text { Cronbach Alpha } \\
\text { (above 0.60) }\end{array}$ & $\begin{array}{c}\text { Critical Ratio } \\
\text { (above 0.60) }\end{array}$ & $\begin{array}{c}\text { Average Variance } \\
\text { Extracted (above } \\
0.50)\end{array}$ \\
\hline Fit & 0.77 & 0.77 & 0.52 \\
Sacrifice & 0.74 & 0.74 & 0.50 \\
Satisfaction & 0.71 & 0.71 & 0.56 \\
\hline
\end{tabular}

The convergent, construct, discriminant validity, together with the internal and composite reliability achieved the required level for sub-constructs of Job Embeddedness. The path analysis and its significance are shown in Table 8.

Table 8: The Regression Weight of Job Embeddedness on its Sub-Constructs and its Significance

\begin{tabular}{|c|c|c|c|c|c|c|c|}
\hline Path & & & Estimate & $\begin{array}{l}\text { Std. } \\
\text { Error }\end{array}$ & $\begin{array}{c}\text { Critical } \\
\text { Ratio }\end{array}$ & $\begin{array}{c}p- \\
\text { value }\end{array}$ & Result \\
\hline Fit & $<--$ & JE & 1.000 & \multicolumn{3}{|c|}{ Reference Point } & Significant \\
\hline Sacrifice & $<--$ & JE & .554 & .135 & 4.105 & *** & Significant \\
\hline Satisfaction & $<-$ & $\mathrm{JE}$ & .756 & 172 & 4.393 & 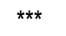 & Significant \\
\hline
\end{tabular}

It is proven that job embeddedness has significant effects on its three sub-constructs, namely, fit, sacrifice and satisfaction. After the issues of uni-dimensionality, validity and reliability of the latent constructs have been addressed, the constructs were modelled into a structural model for analysis using SEM. The final model is shown in Figure 2.

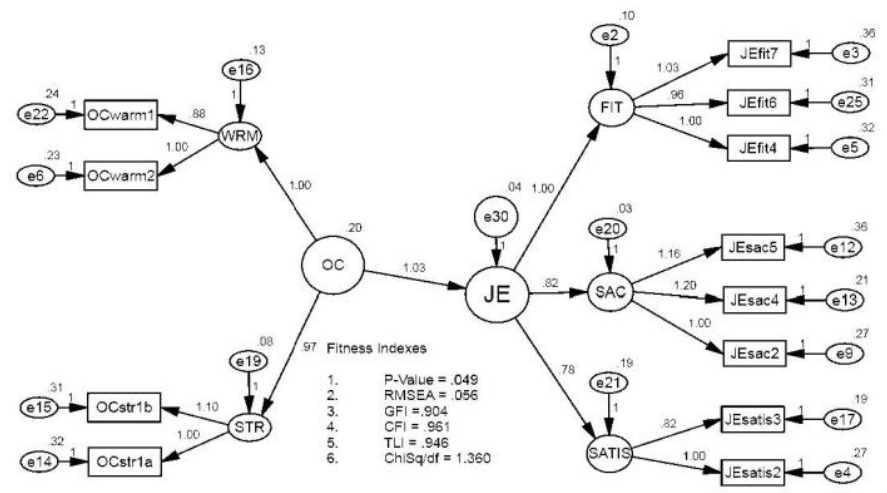

Figure 2: Structural Model with Regression Weights (Unstandardized estimates) 
The fitness indexes assessment for the structural model with respect to absolute, incremental and parsimonious fit achieved the required level with RMSEA $<0.08, \mathrm{GFI}>$ $0.90, \mathrm{CFI}>0.90, \mathrm{TLI}>0.90$ and $\mathrm{ChiSq} / \mathrm{df}<5.0$ as shown in Figure 2 above. Notice that the sub-construct Rewards is not included in the final structural model since its inclusion give a poor fit of the model. This can be due to its low $R^{2}$ of only 0.37 in the second order CFA..The path analysis and its significance for all the constructs and variables in the model are shown in Table 9.

Table 9. The Path Analysis for all Constructs and Variables in the Structural Model

\begin{tabular}{lccccccc}
\hline & Path & & Estimate & SE & CR & J-value & Result \\
\hline JE & $<---$ & OC & 1.028 & .242 & 4.248 & ${ }^{* * *}$ & Significant \\
FIT & $<---$ & JE & 1.000 & \multicolumn{3}{c}{ Reference Point } & Significant \\
SAC & $<---$ & JE & .820 & .162 & $5.046{ }^{* * *}$ & Significant \\
SATIS & $<---$ & JE & .777 & .175 & $4.438{ }^{* * *}$ & Significant \\
WRM & $<---$ & OC & 1.000 & \multicolumn{3}{c}{ Reference Point } & Significant \\
STR & $<---$ & OC & .966 & .217 & $4.448 \quad{ }^{* * *}$ & Significant \\
\hline
\end{tabular}

JE, Job Embeddedness; OC, Organizational Climate; FIT, fit; SAC, sacrifice; SATIS, satisfaction; WRM, warmth; SE, standard error; $C R$, critical ratio

${ }^{* * *} p$-value $<0.001$

All regression weights are found to be significant. The results showed that organizational climate has significant and direct effects on Job Embeddedness. The $\mathrm{R}^{2}$ value is 0.83 , implying that organizational climate contributes $83 \%$ to the prediction of job embeddedness which implied that the final structural model has a good fit with the data collected at hand.

\subsection{Conclusion}

The results have demonstrated that organizational climate has a significant positive relationship with the dimensions in job embeddedness namely fit, link and satisfaction which provide support to the hypothesis. The results are consistent with past studies whereby disabled employees are able to embed with their companies due to the support given by the employer by providing a better organizational climate (Ta \& Leng, 2013) and concern for their welfare (Combs \& Omvig, 1986). Different work group might perceive differently their working and organizational climate which could influence their working outcome. This study has proven the evidence of the need for proper organizational climate that should be address that could encourage disabled employees decision to embed with their current employer. The focus should be given more specially in terms of the warmth and the structure of the organization. Besides, effort must consider on factors to connect and attach the disabled with the company especially the fit, link, and satisfaction aspect. 


\subsection{Limitations}

There are several limitations when considering the outcomes. Firstly, because of the crosssectional nature of the data which was collected at a single point of time, hence, the causality impact cannot be determined. Secondly, the sample consists of disabled employees from the private sector only so that it has limited the generalizability of this study.

\subsection{Practical implications}

This study shows both theoretical and practical research with concerns to the organizational climate and how it influences disabled job embeddedness in the private sector in Malaysia. Organizational climate has been agreed as one of the important basic ingredients for many work outcomes. However, very few empirical studies on organizational climate and disabled job embeddedness in the Malaysian industries have been conducted. Thus, this study has proposed for a better mechanism in linking the organizational climate and job embeddedness among disabled employees. It is indicated that the better the organizational climate; the more embed the disabled employee will be.

\subsection{Directions for future research}

It would be interesting if this study could be replicated to disabled employees in the public sector. It is based on the ideas that there might be different views and unique findings which do not appear in this study. Another future research direction is to examine the possible intermediary or moderating mechanisms that explain the link between organizational climate and job embeddedness. It could be done to look at the associations between the mediating or moderating variables.

\section{References}

Adabi, I. (2011, May 31). Istilah OKU kerapberubah, nasibtetapsama. BeritaHarian, pp. 11.

Aminudin, N. (2011). Gender and employee involvement in Malaysia.JurnalPengurusan, 32, 73-82.

Castro, M. L., \& Martins, N. (2010). The relationship between organizational climate and employee satisfaction in a South African information and technology organization.SA Journal of Industrial Psychology, 36(1), 1-9.

Chen, C., \& Huang, J. (2007). How organizational climate and structure affect knowledge management - The social interaction perspective. International Journal of Information Management, 27, 104-118.

into employment: perceptions of employers. Journal of Rehabilitation, 52, 42-45.

Cotton, J. L., \& Tuttle, J. M. (1986). Employee turnover: A meta analysis and review with implications for research. Academy of Management Review, 11(1), 55-70. 
Denison, D. R. (1996). What is the difference between organizational culture and organizational climate? A native's point of view on a decade of paradigm wars.Academy of Management Review, 21(3), 619-654.

Downey, H. K., Hellriegal, D., Phelps, M., \& Slocum Jr, J. W. (1974). Organizational climate and job satisfaction: A comparative analysis. Journal of Business Research, 2(3), 233-248.

Furuoka, F., Lim, B., Pazim, K. H., \& Mahmud, R. (2011). Employment situation of persons with disabilities: Case studies of US, Japan and Malaysia. Journal of Arts, Science \& Commerce, 2(4), 1-10.

Gentry, W. A., Kuhnert, K. W., Mandore, S.P., \& Page, E. E. (2007). The influence of supervisory-support climate and unemployment rate on part-time employee retention: A multilevel analysis. Journal of Management Development, 26(10), 1005-1022.

Griffeth, R.W., Hom, P.W., \&Gaertner, S. (2000). A meta-analysis of antecedents and correlates of employee turnover: update, moderator tests and research implications for the next millennium. Journal of Management, 26(3), 463-488.

Jackofsky, E. F., \& Slocum Jr, J. W. (1988), A longitudinal study of climates. Journal of Organizational Behavior, 9 , 319-334.

Jones, M. K. (2008). Disability and the labor market: A review of the empirical evidence. Journal of Economic Studies, 35(5), 405-424.

Maertz Jr, C. P., \&Griffeth, R. W. (2004). Eight motivational forces and voluntary turnover: A theoretical synthesis with implications for research. Journal of Management, 30(5), 667-683.

Mitchell, T. R., Holtom, B. C., Lee, T. W., Sablynski, C. J. \&Erez, M. (2001). Why people stay: Using job embeddedness to predict voluntary turnover. Academy of Management Journal, 44(6), 1102-1121.

Pagan-Rodriguez, P. (2009). Onset disability and life satisfaction: An evidence from the German Socio-Economic Panel (GSOEP). European Journal Health Economic, 11, 471- 485.

Patterson, M., Warr, P., \& West.M. (2004). Organizational climate and company productivity: the role of company affect and employee level. Journal of Occupational and Organizational Psychology, 77, 193-216.

Schneider, B., Brief, A. P., \&Guzzo, R. A. (1996).Creating a climate and culture for sustainable organizational change.Organizational Dynamics, 7-19.

Schyns, B., Veldhoven, M. V., \& Wood, S. (2009). Organizational climate, relative psychological climate and job satisfaction.Leadership \& Organization Development Journal, 30(7), 649-663.

Sekiguchi, T., Burton, J. P., \&Sablynski, C. J. (2008). The role of job embeddedness on employee performance: the interactive effects with leader-member exchange and organization-based self-esteem. Personnel Psychology, 61(4), 761-792.

Stone, P. W., Mooney-Kane, C., Larson, E. L., Pastor, D. K., Zwanziger, J., \& Dick, A. W. (2007). Nurse working conditions, organizational climate and intent to leave ICUs: An instrumental variable approach. Health Services Research, 42(3), 1085-1104.

Ta, T. L. \&Leng, K. S. (2013) Challenges Faced by Malaysians with Disabilities in the World of Employment. Disability, CBR \& Inclusive Development, [S.I.], v. 24, n. 1, p. 6-21, may. 2013. ISSN 2211-5242. 
Hashim, H. et.al. / Asian Journal of Quality of Life, AjQoL, 2(6), Apr / Jun 2017 (p.31-42)

Available at: <http://dcidj.org/article/view/142/116>. Date accessed: 19 Oct. 2013. doi:http://dx.doi.org/10.5463/dcid.v24i1.142.

Zainudin, A. (2012). Structural Equation Modeling Using Amos Graphic. Shah Alam: UiTM Press 